\title{
Revista Brasileira de Enfermagem REBEn \\ A percepção dos formandos a respeito dos instrumentos básicos de enfermagem e sua aplicabilidade
}

\author{
The senior students perception about basic nursing tools and their applicability
}

La percepción de los estudiantes del ultimo curso con respecto a los instrumentos basicos de enfermería y sú aplicabilidad

\section{Anesilda Alves de Almeida Ribeiro \\ Enfermeira. Mestre em Enfermagem. Membro da diretoria da ABEn-Regional Itajubá (MG)/ Gestão 2004-2007. aneribe@unifei.edu.br}

\section{Miriam Süsskind Borenstein}

Enfermeira. Doutora em Filosofia da Enfermagem. Professora Adjunto do Departamento de Enfermagem da UFSC.

Este artigo é resultante da dissertação: Ribeiro AAA. A percepção dos formandos a respeito dos instrumentos básicos de enfermagem e sua aplicabilidade [dissertação].

Florianópolis (SC): Departamento de Enfermagem, Universidade Federal de Santa Catarina; 2003.

\section{RESUMO}

Este artigo apresenta um estudo exploratório descritivo da percepção de estudantes de enfermagem sobre a aplicabilidade dos Instrumentos Básicos de Enfermagem (IBE) no cotidiano da prática profissional. Os resultados evidenciam os fatores que contribuem para a continuidade da dicotomia entre teoria e prática e as possibilidades de superação/transformação desta realidade. Além disso, o estudo mostra que a concretização do saber-fazer, em enfermagem, demanda de cada enfermeira a conscientização de que é sua responsabilidade pessoal, profissional e social prestar assistência/cuidado com qualidade, através da aplicação plena dos saberes/ conhecimentos profissionais.

Descritores: Enfermagem; Conhecimento; Cuidados de enfermagem.

\section{ABSTRACT}

This paper presents a descriptive exploratory study of student's perception about the applicability of basic nursing tools on the daily professional practice. Results highlights the factors that contribute to the continuity of dichotomy between theory and practice and the possibilities of overcoming/transformation of this reality. In addition, the study shows that the concretization of the know-how in nursing requires from each nurse to be aware of his/her personal, professional and social responsibility to offer a high quality health care, through the full professional know-how and knowledge.

Descriptors: Nursing; Knowledge; Nursing care.

\section{RESUMEN}

Este artículo presenta un estudio descriptivo-exploratório de la percepción de estudiantes sobre la aplicabilidad de los Instrumentos Básicos de Enfermería (IBE) en la rutina diaria de la práctica profesional. Los resultados evidencian los factores que contribuyen para la continuidad de la dicotomía entre teoría y práctica y las posibilidades de superación/transformación de esta realidad. Además de eso, el estudio muestra que la concretización del saber hacer, en enfermería, demanda de cada enfermera la conscientización de que es de su responzabilidad personal, profesional y social prestar asistencia y cuidado con calidad a través de la aplicación plena de los saberes/conocimientos profesionales.

Descriptores: Enfermería; Conocimiento; Atención de enfermería.

Ribeiro AAA, Borenstein MS. A percepção dos formandos a respeito dos instrumentos básicos de enfermagem e sua aplicabilidade. Rev Bras Enferm 2005 nov-dez; 58(6):653-8.

\section{O TEMA EM EVIDÊNCIA}

A enfermagem ao longo de sua história, vem construindo um corpo de saber/conhecimento instrumentalizando a enfermeira para desenvolver o processo de cuidar com autonomia, responsabilidade e ética. As técnicas de enfermagem, os princípios científicos, as teorias de enfermagem e os Instrumentos Básicos de Enfermagem - IBE (observação, planejamento, método científico, princípio científico, comunicação, trabalho em equipe, destreza manual, criatividade, avaliação e utilização dos recursos da comunidade) são compreendidas, a partir de alguns autores ${ }^{(1,2)}$, como expressões do saber/conhecimento profissional.

Durante 0 curso de graduação, 0 aluno de enfermagem, através de inúmeras experiências tanto no campo teórico, quanto no estágio teórico prático, é capacitado para o exercício profissional legítimo. Entretanto é comum que o novo profissional ao adentrar ao mercado de trabalho, encontre algumas dificuldades para aplicar seus saberes/conhecimentos, principalmente os IBE ${ }^{(3,4)}$.

Considerando-se que os IBE são ferramentas importantes para a prática profissional(5), realizouse este estudo com a finalidade de identificar questões relevantes sobre a constituição, os conflitos e as possibilidades relacionadas à aplicação dos mesmos. Percebendo-se que a inaplicabilidade 
dos saberes/conhecimentos da enfermagem deve-se, em parte, a ausência do exercício de reflexão teórica durante a fase de formação(4), realizou-se este estudo com um grupo de alunos da última fase (formandos) de um Curso de Graduação em Enfermagem do Sul de Minas Gerais. $O$ estudo pautou-se pelo seguinte objetivo: conhecer a percepção de formandos de uma escola de graduação em enfermagem sobre os IBE e sua aplicabilidade no cotidiano da prática profissional.

\section{A METODOLOGIA}

Trata-se de um estudo qualitativo do tipo exploratório descritivo(6) 0 estudo desenvolveu-se na Escola de Enfermagem Wenceslau Braz (EEWB), na cidade de Itajubá/MG, e contou com dezesseis participantes. Os princípios éticos referentes à Resolução 196/96 do Conselho Nacional de Saúde foram respeitados, uma vez que todos os participantes foram orientados quanto ao consentimento livre e esclarecido e a possibilidade de desistir em qualquer fase do processo. 0 estudo obteve a aprovação do Comitê de Ética em Pesquisa da referida escola.

Mediante a estratégia do trabalho em grupo e da técnica de reflexão/ círculo de estudos realizou-se dois encontros, totalizando seis horas de atividades. Os participantes, através do Método do Arco da Problematização(7), observaram a realidade profissional; levantaram os problemas frente a dicotomia entre teoria e prática; elegeram os pontoschave para a teorização; fizeram uma reflexão coletiva buscando compreender os fatores que obstaculizam a aplicação cotidiana dos IBE e apontaram hipóteses de solução para a superação/transformação desta realidade. Os dados foram registrados através de: diário de campo, fotografias, gravação em fita cassete, cartazes e instrumento escrito de avaliação. A análise dos dados, a partir do pensamento de alguns pesquisadores ${ }^{(1,2,5)}$, apontou duas categorias: 1 ) revelando os conflitos entre teoria e prática: as dificuldades de implementação dos IBE; 2) vislumbrando possibilidades de superação/transformação.

\section{RESULTADOS}

3.1 Revelando os conflitos entre teoria e prática: as dificuldades de implementação dos IBE

Analisando os discursos dos participantes, percebe-se que estes têm consciência da importância dos IBE enquanto ferramentas básicas necessárias à assistência de enfermagem com qualidade. Seus discursos mostram, entretanto, que no cotidiano de trabalho este saber/ conhecimento é pouco utilizado pelos alunos e enfermeiras assistenciais, o que tem prejudicado a todos os envolvidos no processo assistir/cuidar.

"Na minha prática acadêmica procuro utilizar os IBE, visando uma melhor assistência ao cliente, porém vejo que muitos profissionais não os aplicam no campo de trabalho. Os que aplicam, apresentam um pouco de falha" (Eva). "A gente acha que a teoria é diferente da prática, porque é isso que a gente vê. Aqui na escola a gente aprende uma coisa e lá na prática é outra. Os funcionários dizem que nós temos a teoria e eles têm a prática" (Margô).

$\mathrm{Na}$ ótica dos participantes, existem vários fatores que contribuem para a continuidade da dicotomia entre teoria e prática, os quais serão abordados a seguir.

\subsubsection{Modelo de ensino}

Num primeiro olhar, os participantes percebem o modelo de ensino como um dos geradores da dicotomia entre teoria e prática, pois a prática encontra-se instituída de uma forma que muitas vezes não favorece o seguimento de algo iniciado durante 0 curso de graduação. 0 modelo de ensino tradicional facilita a continuidade deste problema quando não mostra ao aluno as possibilidades e ferramentas que a equipe de enfermagem tem à disposição para romper/mudar à realidade da prática profissional.

"Na nossa realidade, o que a gente aprende durante as aulas, a gente esquece tudo. Quer dizer, a gente tem quatro anos de estudo para aprender, mas acaba desaprendendo" (Sara).

"A teoria sobre os instrumentos de enfermagem foi bem passada pelos professores. Nós tivemos várias aulas, cada uma sobre um instrumento. Depois, nós fomos para o Hospital para exercitar. Só que essas coisas foram ensinadas tudo em bloco, a gente aprendeu cada instrumento separado e acabou, nunca mais foi cobrado. Não foi preciso mais recordar, revisar esse conteúdo" (Pedro).

Os participantes reconhecem o esforço realizado pelo corpo docente para que os alunos tenham acesso ao conhecimento teórico dos IBE. Todavia, percebem que as estratégias de ensino-aprendizagem adotadas não deixam claro as dimensões e a importância da aplicação dos IBE para toda a vida profissional. Em relação a esse aspecto, Geovanini et $a^{\left({ }^{(8)}\right.}$ afirmam que os instrumentos pedagógicos utilizados pelo ensino tradicional não estão atendendo a demanda de conhecimento vinda dos alunos.

\subsubsection{Modelo de assistência}

Para os participantes, o modelo de assistência é outro agravante da dicotomia entre teoria e prática. Acreditam que isto ocorre, em partes, devido à equipe de enfermagem viver mergulhada numa diversidade de atividades repletas de rotinas e normas que fazem parte da complexa rede que é o seu cenário profissional.

"Realmente é muito diferente a gente ver o que aprendeu na teoria sendo aplicado na prática. Na prática quase nenhum dos instrumentos é usado, porque as enfermeiras fazem tudo diferente do que a gente aprendeu" (Lilica).

"Uma pessoa que não entende sobre a rotina do hospital, sobre 0 dia-a-dia da enfermeira, chega numa Unidade e escuta no interfone: 'enfermeira responsável pela clínica tal, comparecer' então essa pessoa vai pensar que a enfermeira não trabalha. Na verdade, ela está trabalhando em outra clínica também. Então, é muito difícil para ela aplicar os IBE" (Pedro).

Autores como Svaldi e Lunardi Filho( ${ }^{(9)}$ assinalam que a enfermagem contemporânea, por estar imersa em um modelo tradicional de gerenciamento, vem cotidianamente realizando as mesmas rotinas e sofrendo e suportando as condições precárias do mundo do trabalho. Outros $^{(8)}$ afirmam que o modelo curativo de assistência, o biomédico, sobrecarrega a enfermeira com atividades assistenciais e administrativas/gerenciais. Isto a tem conduzido ao desgaste físico e emocional, à falta de oportunidade e tempo para realizar as ações de cuidado e avaliar os resultados.

\subsubsection{Condições de trabalho}

$\mathrm{Na}$ ótica dos participantes, os alunos aplicam pouco os IBE devido, em parte, às condições estruturais inadequadas dos campos de estágio teórico-prático, dentre as quais a falta de recursos humanos e materiais.

"Os hospitais de Itajubá, geralmente têm um número reduzido de funcionários. A enfermeira tem que trabalhar, às vezes, em dois empregos pra tentar suprir suas necessidades. Com isso a gente vê quantidade de serviço e não qualidade. Isto sobrecarrega a enfermeira, mas não justifica o fato dela não usar esses instrumentos no cuidado com o cliente" (Paulo).

As condições estruturais das instituições de saúde constituem uma preocupação antiga da enfermagem. A precursora da enfermagem moderna ${ }^{(10)}$, já no século XIX, afirmava que "condições sanitárias e de arquitetura deficientes e a organização administrativa falha, muitas vezes tornam a prática da enfermagem impossível". Apesar do tempo passado, este problema continua interferindo no saber-fazer da enfermagem até os dias atuais.

Os participantes inferem que, por vezes, a filosofia das instituições hospitalares, ao primar pelo gerenciamento rotineiro, autoritário e a redução de gastos, prejudicam a qualidade da assistência de enfer- 
magem, o que está incoerente, em desacordo com as propostas da Lei do Exercício Profissional(11). Corroborando, Ciancirullo et al ${ }^{(12)}$ afirmam que ao primar pelo lucro e a minimização de gastos financeiros as instituições de saúde estão na contramão do pensamento humanista adotado pela enfermagem. Outros ${ }^{(8)}$ colocam que a exploração da força de trabalho, através dos baixos salários e das condições adversas, a que os profissionais estão sujeitos, contribuem para a baixa qualidade do cuidado.

\subsubsection{Hegemonia do saber médico}

Os participantes apontam a hegemonia do saber médico como outro obstáculo para a aplicação dos IBE e formação do futuro profissional. Afirmam que alguns médicos são contrários às mudanças nos rituais de cuidado, o que limita a autonomia da enfermagem e impede 0 aluno de aplicar os conhecimentos desenvolvidos e adquiridos na escola. Alegam que, por mais que tentem dialogar com estes profissionais, se sentem impedidos de realizarem um cuidado conforme acreditam, de melhor qualidade.

"Os médicos não gostam e não valorizam o trabalho dos alunos de enfermagem. Se a gente fala que determinado cuidado dá mais bem resultado, eles não confiam, e exigem que a gente faça conforme 0 padrão que eles seguem. Isto atrapalha o serviço da enfermagem" (Sara).

A literatura ${ }^{(8)}$ aponta que 0 saber médico dominou 0 ambiente hospitalar a partir do século XVIII, o que justifica o fato desta categoria sentir-se ameaçada, quando a enfermagem reivindica o espaço do cuidado, neste ambiente, em razão do saber/conhecimento profissional que vem desenvolvendo. No enfrentamento destes saberes, a classe médica age de forma autoritária na tentativa de anular o saber da enfermagem.

\subsubsection{Distorção do papel profissional}

Um dos fatores mais graves da dicotomia entre teoria e prática, segundo os participantes, é o conflito no desempenho do papel profissional. Em relação a este item, enfatizam a existência de um excesso de delegação de ações e responsabilidades feitas pela enfermeira aos demais membros da equipe. Pontuam que certas atividades podem ser delegadas, desde que previstas na Lei do Exercício Profissional|(11)

"A enfermeira perdeu um pouco a ação, a liderança e credibilidade. A gente vê que algumas preferem arrumar bandejas e gavetas a observar o cliente, planejar e prescrever os cuidados" (Noêmi).

"Tem enfermeira que chega para o Auxiliar e pede para ele fazer a admissão do cliente e o exame físico. Enquanto isso, ela vai ao laboratório levar algum pedido de exame. Eu vejo que as enfermeiras têm sérias responsabilidades, mas em vez de fazerem o seu trabalho está transferindo suas funções e responsabilidades" (Pedro).

Os discursos evidenciam que, em certas ocasiões, a enfermeira omite-se do exercício de seu papel, desconsiderando as incumbências que Ihes são privativas, dentre as quais a execução de certos cuidados e o planejamento da assistência de enfermagem. Para Rosen ${ }^{(13)}$, 0 "problema de definição de papel", entre os membros da equipe de enfermagem, é uma questão histórica e tem sua raiz no nascimento da enfermagem moderna quando da divisão social de seu trabalho, em cuidadoras (nurses) e educadoras (lady-nurses).

Para os participantes, a falta de conhecimento do Código de Ética ${ }^{(14)}$ e da Lei do Exercício Profissional(11) tem reflexos diretos nas atitudes assumidas pela enfermeira em suas ações cotidianas, e ainda torna seu fazer pouco visível. Reforçam que às vezes o cliente não sabe quem é a enfermeira do setor, pois o que observam é a "invisibilidade" desta profissional(15). Diante desta distorção de papel, os participantes têm dificuldades para compreender o que é Ser-Enfermagem e Ser- enfermeira e se incorporam, diante da dualidade ideal/real, a imagem idealizada ou a visualizada na prática.

"O cliente nunca sabe quem é a enfermeira, o técnico e o auxiliar. Eles chamam todo mundo de enfermeira, porque não tem uma diferenciação" (Rute). "Algumas enfermeiras não entendem bem 0 seu papel" (Paulo).

Outro aspecto evidenciado, pelos participantes, é a ênfase dada pelas enfermeiras às dimensões assistencial e administrativa em detrimento da dimensão didática/educativa e de pesquisa. Esta ênfase tende a negar o papel educador e a dimensão educativa da identidade profissional. Segundo Gastaldo e Meyer ${ }^{(16)}, 0$ atrelamento às dimensões gerenciais afastou a enfermeira do planejamento do cuidado e da dimensão educativa e de pesquisa, o que tem dificultado a produção de novos conhecimentos e o desenvolvimento da profissão.

Para os participantes outro elemento que interfere na dicotomia entre teoria e prática é a mística/cultura do silêncio, que abarca o exercício profissional. Silêncios que impossibilitam ao aluno de fazer críticas e reflexões sobre o cotidiano da prática.

"A gente está estudando e quando 'vê uma coisa errada' se for falar acaba perdendo o campo de estágio. Então, a gente guarda e deixa para mudar quando estivermos atuando como profissionais" (Paulo).

Padilha ${ }^{(17)}$ afirma que alguns dos significados do silêncio são: a omissão (submissão) e a obediência. Elas são características da identidade profissional e da imagem social da enfermagem.

\subsubsection{Padrão limitado de autonomia nas instituições hospitalares}

Os participantes revelam ter mais dificuldades para implementarem os IBE nas instituições hospitalares devido à vivência de um padrão limitado de autonomia. Em contraponto à realidade hospitalar, dizem que os IBE são aplicados na saúde pública de forma mais efetiva e com maior liberdade.

"Nos hospitais, a enfermagem não tem autonomia. Na UBS, a gente tem mais abertura e autonomia para usar todos os nossos instrumentos" (Sara).

Analisando a trajetória da enfermagem institucionalizada percebese que a conquista da autonomia apresentou poucos progressos. Para Gastaldo e Meyer ${ }^{(16)}$ isto se justifica face à conduta dada ao trabalho da equipe de enfermagem, a partir do cumprimento da prescrição médica, das normas e das rotinas administrativas. Neste tipo de gestão, alerta as referidas autoras: corre-se o risco do não reconhecimento da enfermagem como categoria profissional autônoma.

Como exposto, vários são os fatores que obstaculizam a aplicação dos IBE, os quais contribuem para a continuidade da dicotomia entre teoria e prática. Para mudar a realidade vigente, os participantes sugerem algumas estratégias.

\subsection{Vislumbrando possibilidades de superação/transformação}

\subsubsection{Conhecimento dos IBE}

Os participantes percebem a apreensão, aplicação e transformação cotidiana dos IBE como um dos caminhos para o crescimento profissional, a superação da dicotomia entre teoria e prática, 0 enfrentamento dos conflitos do dia-a-dia, a conquista de espaços e a melhoria da qualidade do cuidado. Corroborando, Sampaio e Pellizzetti(18) afirmam que a resolução, eficiente e eficaz, dos questionamentos da enfermagem clama pelo usufruto dos saberes/conhecimentos profissionais. Portanto, é preciso dominá-los, o que pode ser adquirido através de leituras, exaustiva análise crítica e insaturação no uso dos mesmos.

"Sem os saberes da enfermagem, os IBE, a profissão morre. Então eu acho que nós não devemos deixar de lado os IBE. Nós devemos utilizar e modificar quando necessário, pois só assim iremos prestar 


\section{um cuidado com qualidade" (Sara).}

Ressalta-se que a mera aplicação dos IBE só para atender a uma exigência curricular é grave. Os alunos, docentes e enfermeiras assistenciais precisam ter consciência da importância desse conhecimento levado à prática, pois proporcionam uma justificativa para a tomada de decisão, facilitam os relacionamentos interpessoais e as ações de cuidado. Portanto, este saber profissional deve estar, imperativamente, vinculado à prática.

\subsubsection{Conhecimento da Lei do Exercício Profissional}

Os participantes afirmam que sendo a enfermagem uma profissão na qual as minúcias e os detalhes abarcam seu cotidiano, é preciso que a enfermeira assuma o seu papel, senão outro profissional o fará. Pois, é nas pequenas perdas do dia-a-dia que a nossa profissão vai se desfazendo, perdendo sentido e visibilidade.

"Se a enfermeira não assumir o seu papel, alguém vai ter que ocupar: o técnico, o auxiliar e até o médico" (Bahianinha).

Para minimizar os problemas relativos ao papel profissional, os participantes recomendam que a equipe de enfermagem repense e reflita sobre sua realidade. Acreditam que ao repensar coletivamente a postura profissional, a equipe de enfermagem poderá melhorar seu desempenho e a imagem que propaga e é percebida pela sociedade.

"A enfermeira não deve abandonar nunca o seu papel. Quando abandona, cai numa rotina de fazer um trabalho muito próximo ao do auxiliar ou técnico. Isto porque desconhece as competências de cada um" (Edna).

Para o enfrentamento e resolução do conflito de papéis, os participantes sugerem o conhecimento das competências e responsabilidades de cada elemento da equipe definidas pela Lei do Exercício Profissional(11), a revisão dos conceitos e da filosofia de trabalho. Acreditam que com isto cada membro da equipe de enfermagem irá desenvolver e revelar à clientela uma postura mais profissional.

"Não é só a teoria que conta para você praticar a enfermagem. Você precisa de todo um conjunto de habilidades, vivência, carga e bagagem para assumir seu papel e ser uma enfermeira por inteiro. Para isso a gente precisa ter consciência do quê a gente está fazendo, do quê a gente quer. Pois, se eu quero fazer Enfermagem, eu vou fazer Enfermagem. Eu não estou ali para desfilar uma roupinha branca e achar que devo fazer só a evolução do cliente e assinar o prontuário. Ser enfermeira é mais do que isso" (Sara).

Acredita-se que, para a equipe de enfermagem trabalhar em conformidade com a Lei do Exercício Profissional(11), seria interessante todos os profissionais terem às mãos o texto da referida lei e demais documentos que a suplementam, bem como o Código de Ética ${ }^{(14)}$. Além disso, poderiam promover encontros ou grupos de discussão, para debaterem amplamente sobre as dúvidas suscitadas no cotidiano profissional. Estes momentos reflexivos poderiam contribuir para um desempenho profissional mais consciente, eficiente e seguro.

\subsubsection{Comprometimento da enfermeira}

Os participantes percebem que o maior potencial de mudança, na enfermagem, é o próprio profissional, pois é de responsabilidade de cada enfermeira fazer a diferença no cotidiano da prática. Reconhecem que cada membro da equipe tem potencial para mudar a realidade, apesar da escassez de tempo e dos demais fatores que obstaculizam 0 saber-fazer.

"A enfermeira não deve ficar parada no tempo fazendo do mesmo jeito, sempre. Nós temos que mudar, fazer diferente senão a enfermagem retrocede. É nossa responsabilidade. Depende de nós fazermos as mudanças" (Sara).

Para que haja aderência, disposição e envolvimento dos profissionais de enfermagem no desenvolvimento dos IBE, ou de qualquer outra atividade de enfermagem, os participantes percebem a necessidade de estímulo e sensibilização.

Enquanto aluno, temos que desenvolver bem o trabalho e aplicar esses instrumentos na prática para mostrar para as enfermeiras que a gente sabe aplicar. Quem sabe assim a gente consegue despertar nelas o interesse, à vontade de pegar mesmo para conhecer e aplicar estes saberes (Ester).

O discurso dos participantes deixa evidente que as mudanças, necessárias na prática de enfermagem, precisam iniciar-se pelo comprometimento dos seus agentes. Para tanto, é preciso que haja a transformação da comodidade em compromisso, pois "é inaceitável ao ser humano crítico a reprodução do velho discurso de que "não há o que fazer"(19).

$\mathrm{Na}$ cotidianidade, a enfermagem precisa evoluir, aproveitar as oportunidades e conquistar os espaços de cuidado, usando plenamente os seus saberes/conhecimentos. É preciso deixar de lado os afazeres domésticos. Para superar/transformar a realidade vigente é preciso que o profissional esteja apaixonado pelo saber-fazer diário, que busque 0 conhecimento, tenha coragem, vontade e ousadia para romper com 0 instituído. Ele deve mudar a sua postura de comodidade para uma postura mais comprometida e profissionalmente responsável, pois é cômodo aos profissionais permanecerem rigidamente numa posição de defesa sem nada fazer para a concretude ${ }^{(20)}$ da enfermagem idealizada.

\subsection{4 Ênfase no trabalho em equipe}

Para os participantes, qualquer mudança na enfermagem depende em primeiro lugar de um trabalho individual e posteriormente de um coletivo. Do mesmo modo, de um trabalho colaborativo entre os elementos do ensino e da assistência. Neste sentido, alguns autores enfatizam que "da ação conjunta das enfermeiras depende o progresso da profissão"(21), pois o trabalho em equipe favorece 0 crescimento individual e coletivo ${ }^{(22)}$. Em grupo, conseguimos avançar, aprofundar discussões, ampliar conhecimentos e melhor conduzir o processo de evolução da profissão, de forma a superar as dificuldades e obter maior autonomia.

"Para que a gente tenha autonomia, a enfermeira da unidade precisa dar as mãos aos alunos porque, a gente deveria ter união com a enfermeira do setor. Um deve sempre estar ao lado do outro. Nós alunos o que queremos é aprender com ela e, também, ter a autonomia que é de direito nosso" (Margô).

A autonomia, dilema antigo e ao mesmo tempo atual, na área de enfermagem, pode ser conquistada através de um efetivo trabalho em equipe. Desse modo, é preciso que haja diálogo e interação positiva entre os envolvidos. Salienta-se que os alunos e docentes precisam unir forças com a equipe de enfermagem que atua nas instituições hospitalares para que possam, juntos, promover as mudanças necessárias na prática profissional e conseqüentemente o desenvolvimento da profissão. Sendo assim, é imprescindível que haja espírito de equipe e união entre os diversos seguimentos da profissão.

\subsubsection{Adoção de novas estratégias de ensino-aprendizagem}

O tom do discurso dos participantes mostra que o ensino de enfermagem, a partir do uso da estratégia de aula expositiva, não consegue mais responder à variedade de realidades nas quais a prática de enfermagem ocorre.

"Essa metodologia problematizadora é diferente, quase não a vivenciamos nesses anos de graduação. É produtiva e fez com que usássemos nossa 'memória, consciência', pensamentos e crítica do que estamos fazendo e o quanto podemos fazer para melhorar nosso trabalho (Raquel).

Os participantes acreditam que o ensino de enfermagem precisa valer-se de metodologias, técnicas e estratégias inovadoras que contemplem uma reflexão crítica, o trabalho coletivo e o diálogo horizontal. Assim sendo, o futuro profissional estará mais bem preparado para enfrentar as dicotomias, ambigüidades, conflitos, crises e os 
silêncios do dia-a-dia da prática. Sobre este aspecto, Gastaldo e Meyer ${ }^{(16)}$ pontuam que: "as escolas de enfermagem só formarão profissionais realmente aptos a avançar na enfermagem, quando permitirem que as contradições existentes na profissão aflorem e sejam tratadas ao longo do processo de formação".

Destaca-se que, na realidade da formação profissional, as questões que borbulham das observações feitas pelos alunos precisam ser refletidas coletivamente. Ao encontrarmos contradições, precisamos trazê-las para a discussão, pois estas questões servem para impulsionar o processo de mudança. Não se pode 'aplicar gelo' nas inquietações dos alunos, contribuindo para a continuidade da submissão profissional e da mística/cultura do silêncio. É preciso colocar 'compressas quentes' e deixar os conflitos e crises explodirem, para fortalecer os novos profissionais capacitando-os a encontrar saídas para a superação/ transformação da dicotomia entre teoria e prática. Corroborando, Freire ${ }^{(23)}$ afirma que "a reflexão crítica sobre a prática se torna uma exigência da relação Teoria/Prática, sem a qual a teoria pode ir virando blablablá e a prática, ativismo".

\subsubsection{Mudanças na filosofia institucional}

Considerando que entre as funções e responsabilidades do hospital moderno, encontram-se a de contribuição com o ensino, com a pesquisa e a formação dos novos profissionais ${ }^{(13)}$ os participantes percebem e julgam necessárias algumas mudanças em sua filosofia para melhorar a formação profissional em enfermagem.

"A instituição em si precisa rever suas normas, filosofia porque elas atrapalham o serviço de enfermagem" (Paulo).

Outros investimentos vistos como pertinentes pelos participantes são a promoção de encontros e cursos, a criação de Serviços de Apoio Educacional, de Centros/círculos de Estudos, de Grupos de Discussão e de Núcleos de Pesquisas, com o objetivo de promover a atualização e qualificação técnica-científica da equipe de enfermagem e a reflexão crítica sobre o cotidiano da prática.

\subsubsection{Melhorias nas condições de trabalho}

O discurso dos participantes evidencia que as instituições de saúde, acolhedoras dos alunos precisam adequar seus campos de estágio para a otimização do serviço de enfermagem e a aplicação prática dos conteúdos teóricos adquiridos na escola. Isto requer, de acordo com a demanda de cuidados, um planejamento e adequação do número de profissionais e a disponibilização de materiais e equipamentos em boas condições de uso.

"Se lá fora o hospital visa o atendimento integral ao cliente e com qualidade e para isso tem uma maior quantidade de funcionários

\section{REFERÊNCIAS}

1. Almeida MCP, Rocha JSY. O saber de enfermagem e sua dimensão prática. São Paulo (SP): Cortez; 1989.

2. Horta WA. Processo de Enfermagem. São Paulo (SP): EPU; 1979.

3. Fortes AFA. Há falhas por parte de todos os atores: visão do enfermeiro assistencial sobre o Estágio Curricular Supervisionado [dissertação]. Belo Horizonte (MG): Escola de Enfermagem, Universidade Federal de Minas Gerais; 2001.

4. Ribeiro WFP. Do projeto político pedagógico à identidade social: 0 processo de avaliação da EEWB segundo seus egressos. [dissertação]. Campinas (SP): Faculdade de Educação, Pontifícia Universidade Católica; 2000.

5. Cianciarullo $\mathrm{TI}$, organizadora. Instrumentos básicos para o cuidar: um desafio para a qualidade da assistência. São Paulo (SP): Atheneu; 2000.

6. Triviños ANS. Introdução à pesquisa em ciências sociais: a pesquisa qualitativa em educação. São Paulo (SP): Atlas; 1987.

7. Bordenave JED, Pereira AM. Estratégias de ensino-aprendizagem $22^{\mathrm{a}}$. ed. Petrópolis (RJ): Vozes; 2001. então, aqui a gente precisa ter igual. Assim vamos aplicar os IBE e prestar uma melhor assistência" (Paulo).

Svaldi e Lunardi Filho( ${ }^{(9)}$ sugerem, em relação à mudança estrutural, que a enfermagem reivindique ambientes mais organizados e adequados para o trabalho. Ressaltam que as figuras-chave, para tais reivindicações, são as líderes que assumem também cargos de diretoria/ gerência. Afirmam que estas gerentes precisam perceber-se como elo de ligação entre a equipe de enfermagem e a direção da instituição de saúde e, por conseguinte, primar pelo desenvolvimento da profissão e, principalmente, defender os interesses da categoria.

\section{CONSIDERAÇÕES FINAIS}

Através da reflexão sobre os IBE e sua aplicabilidade, foram identificadas algumas das particularidades que conduzem à dicotomia entre teoria e prática. A realidade desvelada pelos discursos dos participantes mostra a continuidade de alguns fatores que obstaculizam o saber-fazer da enfermagem e, conseqüentemente, contribuem para a invisibilidade e desvalorização do seu trabalho.

A enfermagem está vivenciando, revelam os discursos, um momento favorável a significativas transformações. Elas serão concretizadas, se as enfermeiras forem capazes, de compreendidas as barreiras ao crescimento da profissão, buscarem os meios e estratégias para elevar a enfermagem à posição que lhe é devida. Ressalta-se que as conquistas na enfermagem devem ser contínuas. E que o caminho a ser percorrido, rumo a evolução da profissão, se dá pelo aperto de mãos, união de idéias, desejo dos membros da equipe de defenderem seus ideais e se perceberem providos de recursos para mudar a realidade vigente.

De acordo com os relatos, se a enfermeira souber incorporar seu espírito crítico às tecnologias do saber/conhecimento profissional valorizará os aspectos mais sublimes e nobres da profissão: a vocação para acolher, cuidar e educar com competência. Adicionalmente, a atualização e qualificação profissional contribuiriam para a mudança da imagem de submissão, docilidade e obediência que acompanha a Enfermagem ao longo da história ${ }^{(17,24)}$.

Finalizando, infere-se que as mudanças necessárias para a concretização do saber-fazer em enfermagem e a ruptura frente à dicotomia entre teoria e prática demandam, de cada enfermeira, a conscientização de que é sua responsabilidade - pessoal, profissional e social - prestar assistência/cuidado com qualidade. Isto requer que esteja comprometida com a aplicação plena, no cotidiano da prática, dos saberes/conhecimentos profissionais, principalmente, dos instrumentos básicos de enfermagem.

8. Geovanini T, Moreira A, Dorneles S, Machado WCA. História da enfermagem: versões e interpretações. Rio de Janeiro (RJ): Revinter; 1995.

9. Svaldi JSD, Lunardi Filho WD. Poder e gerenciamento na enfermagem. Texto \& Contexto: Enferm 2000 ago-dez; 9(3):22-41.

10. Nightingale F. Notas sobre enfermagem: o que é e o que não é. São Paulo (SP): Cortez; 1989.

11. Conselho Federal de Enfermagem. Lei $n^{\circ} 7498$, de 25 de junho de 1986. Dispõe sobre a regulamentação do exercício da Enfermagem e dá outras providências. Brasília (DF), 1986.

12. Cianciarullo TI, Gualda DMR, Melleiro MM, Anabuki MH. Sistema de Assistência de Enfermagem: evolução e tendências. São Paulo (SP): Ícone; 2001.

13. Rosen G. Da polícia médica à medicina social: ensaios sobre a história da assistência médica. Rio de Janeiro (RJ): Graal; 1980.

14. Conselho Federal de Enfermagem. Resolução n ${ }^{\circ}$ COFEN-240/2000, de 30 de agosto de 2000. Aprova o Código de Ética dos Profissionais de Enfermagem e dá outras providências. Rio de Janeiro; 2000. 
15. Souza JG. Autonomia e cidadania na enfermagem. Rev Bras Enferm 2000 ago/dez; 9(3):86-99.

16. Gastaldo DM, Meyer DE. A formação da enfermeira: ênfase na conduta em detrimento do conhecimento. Rev Bras Enferm 1989 jan-dez; 42(1/4): 7-13.

17. Padilha MICS. A mística do silêncio: a enfermagem na Santa Casa de Misericórdia do Rio de Janeiro no século XIX. Pelotas (RS): Ed. Universitária/UFPEL; 1998.

18. Sampaio LABN, Pellizzetti N. Método Científico: Instrumento Básico da Enfermeira. In: Cianciarullo TI, organizadora. Instrumentos básicos para o cuidar: um desafio para a qualidade da assistência. São Paulo: Atheneu; 2000. p.25-38

19. Freire P. Educação e Mudança. $18^{\mathrm{a}}$ edição. Rio de Janeiro (RJ): Paz e Terra; 1979
20. Saupe R. Ação e reflexão na formação do enfermeiro através dos tempos. In: Saupe R, organizador. Educação em Enfermagem. Florianópolis (SC): UFSC; 1998. [s.p.].

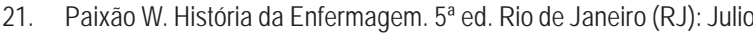
C. Reis; 1979.

22. Silva DMGV, Francioni FF, Natividade MSL, Azevedo M, Sandoval RCB, Di'Lorenzo VM. Grupos como possibilidades para desenvolver educação em saúde. Texto \& Contexto: Enferm 2003 jan-mar; 12 (1): 97-103.

23. Freire P. Pedagogia da Autonomia: saberes necessários à prática educativa. 23a ed. São Paulo (SP): Paz e Terra; 1996.

24. Ribeiro AAA, Borenstein MS. Escola de Enfermagem Wenceslau Braz: trajetória e construção da identidade profissional da enfermagem em Itajubá/MG. Texto \& Contexto: Enferm 2003 outdez; 12 (4): 470-9. 